\title{
A giant mucinous cystadenocarcinoma of the appendix: a case report and review of the literature
}

\author{
Hiroshi Nagata ${ }^{1 *}$, Yuji Kondo ${ }^{1,2}$, Kazushige Kawai ${ }^{1}$, Soichiro Ishihara', Shinsuke Kazama', Takako Nirei ${ }^{1,2}$, \\ Daisuke Soma ${ }^{1,2}$, Jun Yamada', Eiji Sunami ${ }^{1}$, Joji Kitayama', Yoshiro Kubota ${ }^{2}$ and Toshiaki Watanabe ${ }^{1}$
}

\begin{abstract}
Background: Mucinous cystadenocarcinoma is the second most common etiology of appendiceal mucocele. We report a relatively rare case of a giant appendiceal mucocele caused by mucinous cystadenocarcinoma, which occupied the entire abdomen of an adult woman.

Case presentation: A 63-year-old woman presented with a chief complaint of abdominal distention. Imaging studies showed a giant cystic mass occupying her entire abdomen. Laparotomy confirmed a giant appendiceal mucocele, and the patient underwent ileocecal resection. A mucinous deposit was not found in her abdominal cavity, and the ovaries were grossly normal bilaterally. The pathological diagnosis was mucinous adenocarcinoma with a low-grade mucinous neoplasm that invaded the subserosa. Regional lymph node metastasis was not found. She has had recurrence-free survival for 5 years.

Conclusions: The present case is the largest appendiceal cystadenocarcinoma ever reported. The optimal treatment of an appendiceal neoplasm requires further research based on consensus terminology of an appendiceal mucocele.
\end{abstract}

Keywords: Mucinous cystadenocarcinoma, Appendix, Mucocele

\section{Background}

Mucinous cystadenocarcinoma is the second most common etiology of appendiceal mucocele [1, 2], and it is usually a well-differentiated, slowly progressive neoplasm. The gross morphology is indistinguishable from other types of mucoceles, but it is easy to perforate them before a giant cystic tumor is produced. We report a relatively rare case of a giant appendiceal mucocele caused by mucinous cystadenocarcinoma, which occupied the entire abdomen of an adult woman.

\section{Case presentation}

A previously healthy 63-year-old woman presented with a chief complaint of abdominal distention. She denied abdominal pain, nausea, or constipation. She also did not have

\footnotetext{
* Correspondence: hinagata-tky@umin.ac.jp

${ }^{1}$ Division of Surgical Oncology, Department of Surgery, Faculty of Medicine,

The University of Tokyo, 7-3-1 Hongo, Bunkyo-ku, Tokyo 113-8655, Japan

Full list of author information is available at the end of the article
}

any relevant medical history. Her abdomen was remarkably distended but was soft and nontender. Blood test indicated slight anemia of hemoglobin (10.2 g/dL; normal range, $11.6-14.8 \mathrm{~g} / \mathrm{dL}$ ) and increased levels of the carcinoembryonic antigen (CEA) and cancer antigen 19-9 (CA19-9) to $406.1 \mathrm{ng} / \mathrm{mL}$ (normal range, $0-5.0 \mathrm{ng} / \mathrm{mL}$ ) and $66 \mathrm{U} / \mathrm{mL}$ (normal range, $0-37.0 \mathrm{U} / \mathrm{mL}$ ), respectively. The CA-125 level was normal.

Contrast-enhanced computed tomography (CT) showed a well-encapsulated, unilocular cystic mass with focal mural calcification. It occupied her entire abdomen from just below the diaphragm to the pelvis, and it measured $40.2 \mathrm{~cm}$ in length (Fig. 1). Magnetic resonance imaging (MRI) demonstrated a cystic mass with high signal intensity on T2-weighted images and intermediate signal intensity on T1-weighted images (Fig. 2). These imaging studies also showed a dendritic structure protruding into the cavity, and the feeding artery originated from a branch of the ileocecal artery. Extrinsic obstruction due to the giant mass 


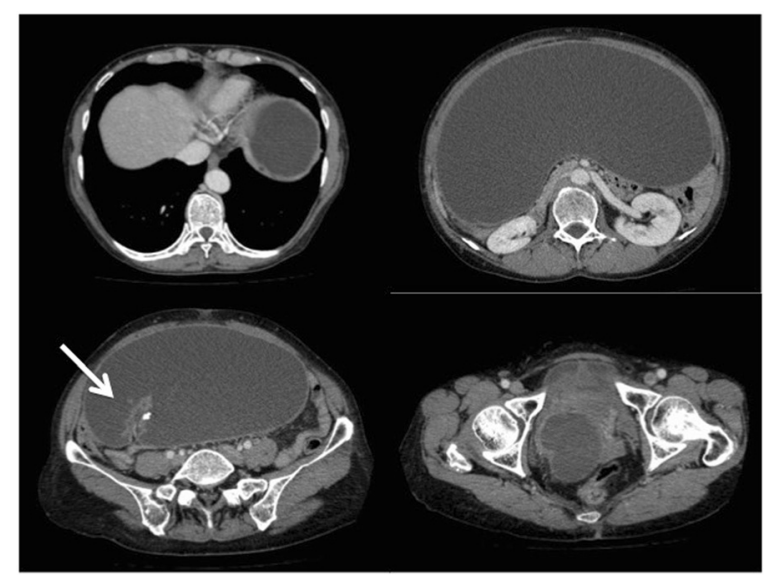

Fig. 1 Contrast-enhanced computed tomography showed a well-encapsulated, unilocular cystic mass which occupied the entire abdomen from just below the diaphragm to the pelvis. Arrow showed a dendritic structure protruding into the tumor cavity

was identified on colonoscopy, but the orifice of the appendix remained intact. Based on these results, our preoperative diagnosis was a large neoplastic mucocele of the appendix.

Laparotomy showed the enlarged appendix, which occupied the entire abdomen. A mucinous deposit was not found in her abdominal cavity, and the ovaries were grossly normal bilaterally. Even though the cyst adhered strongly to the abdominal wall due to inflammation, ileocecal resection was performed uneventfully.

The cystic mass contained about $7000 \mathrm{~mL}$ of serous fluid. The levels of CEA and CA19-9 in the fluid were $57,905 \mathrm{ng} / \mathrm{mL}$ and $1380 \mathrm{U} / \mathrm{mL}$, respectively. Macroscopically, a cross-section of the mass showed a cystically dilated lumen containing mucin, and the portion protruding from the appendiceal lumen looked like a villous
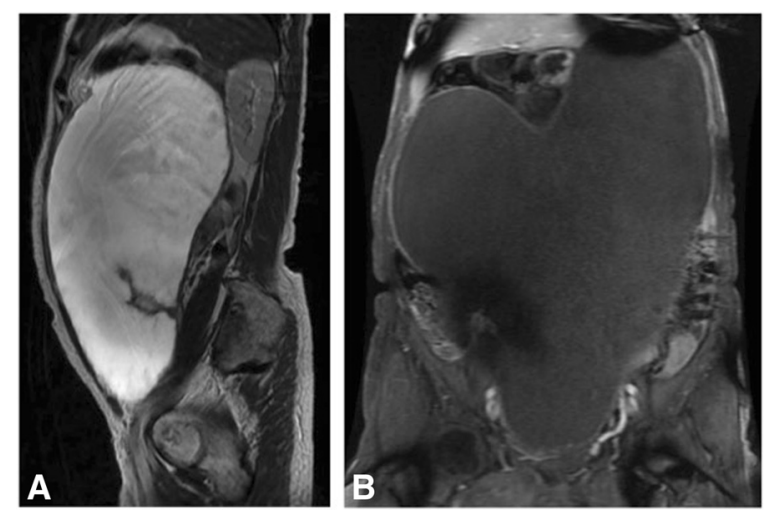

Fig. 2 Magnetic resonance imaging demonstrated a giant unilocular cystic mass with high signal intensity on T2-weighted images (a) and intermediate signal intensity on T1-weighted images (b) tumor (Fig. 3). The histopathological diagnosis was a mucinous adenocarcinoma with a low-grade mucinous neoplasm that had invaded the wall into the subserosa (Fig. 4). Regional lymph node metastasis was not detected. The levels of CEA and CA19-9 were within normal range 3 months postoperatively, and the patient has had recurrence-free survival for 5 years.

\section{Discussion}

We report a rare case of a giant appendiceal mucocele caused by mucinous cystadenocarcinoma, which occupied the entire abdomen of an adult woman.

An appendiceal mucocele is a morphologic entity referring to the distention of the appendicular lumen due to the accumulation of mucus. It has been a long time since it was first described by Rokitansky [3], but the terminology for appendiceal mucocele has not been agreed on [4]. Mucoceles of the appendix have been classified into four types: (1) a simple mucocele or retention cyst resulting from obstruction of the appendiceal outflow, (2) mucosal hyperplasia, (3) a benign mucinous cystadenoma, and (4) a mucinous cystadenocarcinoma [5, 6]. A mucinous cystadenocarcinoma is the second most common etiology after mucinous cystadenoma, and it accounts for 11 to $20 \%$ of cases of appendiceal mucoceles.

Although luminal dilatation is mild (up to $1 \mathrm{~cm}$ ) in retention mucocele and hyperplasia, mucinous cystadenoma and cystadenocarcinoma often exhibit marked distention [7]. We searched PubMed for publications on mucoceles of the appendix with the keywords "giant" and "large," and there have been about 50 cases reported from 1919 to 2015. The median diameter was $13 \mathrm{~cm}$, and the largest mucocele ever reported was $40 \mathrm{~cm}$ in diameter, which was caused by a mucinous cystadenoma [8]. The majority of these giant mucoceles were caused by mucinous cystadenomas, whereas cystadenocarcinomas were the cause of only a few cases [9-14]. Therefore, the present case is rare in two respects: it is the largest mass among all types of appendiceal mucoceles, and it is a giant mucocele caused by a cystadenocarcinoma.

A mucocele is usually diagnosed by an abdominal CT scan. The typical finding of an appendiceal mucocele is a low attenuated, well-encapsulated, thin-walled cystic mass in the right lower quadrant. Mural calcification is seen in less than $50 \%$ of cases [6]. MRI demonstrates a mass with intermediate signal intensity on T1-weighted images and homogeneous high signal intensity on T2weighted images $[15,16]$. An enhancing nodule in the mucocele wall is suggestive of a cystadenocarcinoma. In the present case, the dendritic structure within the cystic cavity was a clue to suspect malignancy.

However, the precise preoperative distinction between a cystadenoma and cystadenocarcinoma is often difficult $[17,18]$. The tumor marker level is insufficient for an 

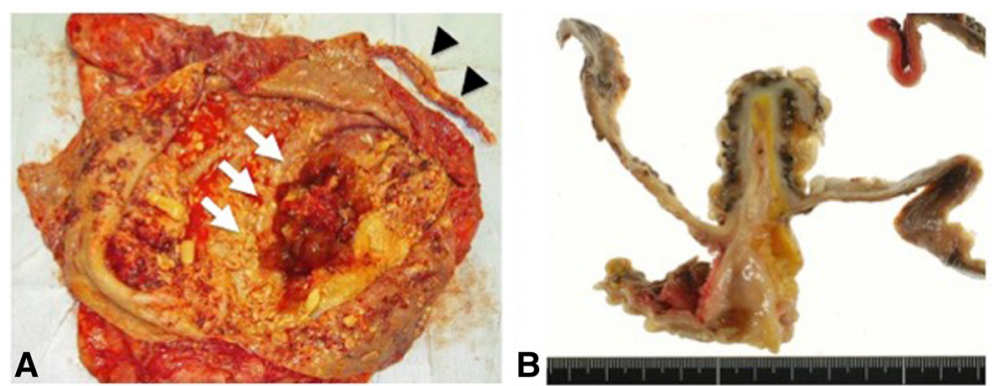

Fig. 3 a A cross-section of the mass showed a cystically dilated lumen with the portion protruding from the appendiceal lumen (arrow). b A magnified view of the dendritic structure which appeared as a villous tumor

accurate diagnosis, because it is still unclear whether there is a difference in the serum or cystic fluid of CEA and CA19-9 levels between cystadenomas and cystadenocarcinomas $[19,20]$.

The boundary between cystadenomas and cystadenocarcinomas is ambiguous even in a pathological study. The term "mucinous tumor of low malignant potential" [21] or "low-grade appendiceal mucinous neoplasm" [22] was introduced to describe intermediate grades between cystadenomas and cystadenocarcinomas [23]. Furthermore, various subclassifications have been proposed according to the presence of acellular peritoneal mucin deposits or extra-appendiceal neoplastic epithelium [21, 22].

The Peritoneal Surface Oncology Group International recently reported the consensus for classification and pathologic reporting [24]. It argues that the term "cystadenoma" should no longer be used as a diagnostic term with regard to the appendix. Mucinous adenocarcinoma is defined as a mucinous tumor with infiltrative invasion. Mucinous neoplasm with low-grade cytologic atypia is classified as low-grade appendiceal mucinous neoplasm (LAMN) regardless of its associated features. The term "high-grade appendiceal mucinous neoplasm" was proposed for lesions with low-grade architectural features similar to LAMN but with high-grade cytologic features.

The operative strategy is also changing. It was the standard concept, and it still is in many facilities, that if the histological diagnosis is hyperplasia or cystadenoma, appendectomy is the definite treatment, but if it is a cystadenocarcinoma, resection should be combined with right colectomy [25, 26]. However, appendectomy combined with excision of all the mesoappendiceal fat can be adequate in patients with a cystadenocarcinoma in the absence of mesenteric adjacent organ or peritoneal involvement $[27,28]$. Obviously, right hemicolectomy is advised if tumor clearance is required.

Formerly, an appendiceal mucocele was considered an indication for open surgery, but now, many surgeons think that laparoscopic appendectomy is a reasonable choice when treating a mucocele of the appendix [29]. However, extreme care is imperative to avoid underestimating the extent of the disease and prevent iatrogenic rupture and dispersion of mucus or epithelial cells into the peritoneal cavity during the surgical procedure. In the current case, we converted to open ileocecal resection to achieve curative operation without causing intraoperative rupture.

\section{Conclusions}

We describe the case of an adult woman with the largest mucinous cystadenocarcinoma of the appendix that occupied the entire abdomen. The optimal treatment of appendiceal neoplasm requires further research based on consensus terminology of an appendiceal mucocele.
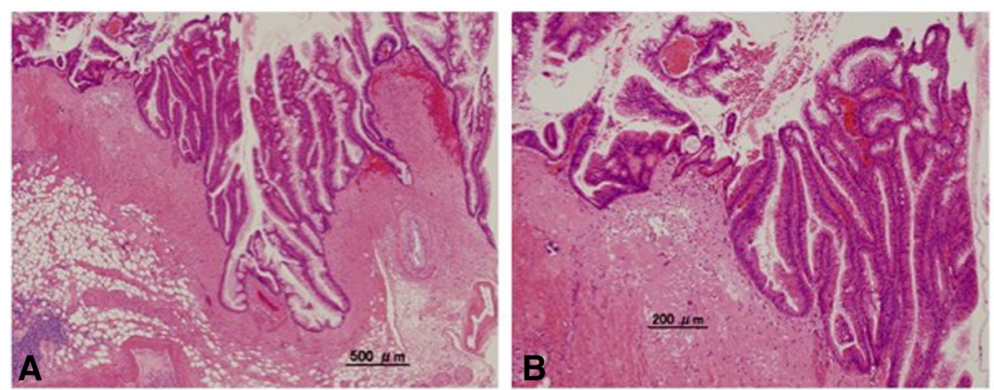

Fig. 4 a Microscopical view of the tumor showed a mucinous adenocarcinoma, and a low-grade mucinous neoplasm is intermingled (hematoxylin and eosin stain, $\times 20$ ). b Adenocarcinoma is observed to invade the subserosa of the appendix (hematoxylin and eosin stain, $\times 50$ ) 


\section{Consent}

Written informed consent was obtained from the patient for publication of this Case report and any accompanying images. A copy of the written consent is available for review by the Editor-in-Chief of this journal.

\section{Abbreviations}

CA: cancer antigen; CEA: carcinoembryonic antigen; CT: computed tomography; LAMN: low-grade appendiceal mucinous neoplasm; MRI: magnetic resonance imaging.

\section{Competing interests}

The authors declare that they have no competing interests.

\section{Authors' contribution}

HN, YKo, and SK wrote the manuscript, and HN reviewed the literature; KK, NT, DS, JY, and YKu helped to draft the manuscript; TW, SI, and JK reviewed the manuscript; YKo and SK cared for the patient; SK carried out the pathological diagnosis, and ES provided clinical images. All authors read and approved of the final manuscript.

\section{Author details}

'Division of Surgical Oncology, Department of Surgery, Faculty of Medicine, The University of Tokyo, 7-3-1 Hongo, Bunkyo-ku, Tokyo 113-8655, Japan. 2Department of Surgery, Kikkoman General Hospital, 100 Miyazaki, Noda-city, Chiba 278-0005, Japan.

Received: 14 August 2015 Accepted: 1 March 2016

Published online: 05 March 2016

\section{References}

1. Higa E, Rosai J, Pizzimbono CA, Wise L. Mucosal hyperplasia, mucinous cystadenoma, and mucinous cystadenocarcinoma of the appendix. A re-evaluation of appendiceal "mucocele". Cancer. 1973:32:1525-41.

2. Aranha GV, Reyes CV. Primary epithelial tumors of the appendix and a reappraisal of the appendiceal "mucocele". Dis Colon Rectum. 1979:22:472-6.

3. Rokitansky CF. A manual of pathological anatomy. Philadelphia: Blanchard \& Lea; 1855

4. Rabie ME, Al Shraim M, Al Skaini MS, Alqahtani S, El Hakeem I, Al Qahtani AS, et al. Mucus containing cystic lesions "mucocele" of the appendix: the unresolved issues. Int J Surg Oncol. 2015;2015:139461.

5. Soweid AM, Clarkston WK, Andrus CH, Janney CG. Diagnosis and management of appendiceal mucoceles. Dig Dis. 1998;16:183-6.

6. Dixit A, Robertson JH, Mudan SS, Akle C. Appendiceal mucocoeles and pseudomyxoma peritonei. World J Gastroenterol. 2007;13:2381-4.

7. Rampone B, Roviello F, Marrelli D, Pinto E. Giant appendiceal mucocele: report of a case and brief review. World J Gastroenterol. 2005;11:4761-3.

8. Wallis JW, Madan A, Shoemaker MC. Giant mucocele of the appendix. AJR Am J Roentgenol. 1995;165:1013-4

9. Arly KS, Stephenson Jr DV, Davis WC. Giant retroperitoneal mucocele simulating pseudomyxoma peritonei and mucinous adenocarcinoma. Am J Surg. 1968;116:439-43.

10. Gerritsen $K G$, Slee PH, Bollen TL, van Hecke W, Seldenrijk CA, Keijsers RG, et al. Recurrent pneumonia due to an appendiceal mucinous cystadenocarcinoma: a rare presentation of a rare malignancy. Clin Med Oncol. 2009:3:9-12

11. Hayashi T, Kawahara H, Yoshimoto K, Kashiwagi H, Yanaga K, Komine K. Early cystoadenocarcinoma of vermiform appendix simulating submucosal tumor of the cecum. Int J Surg. 2008:6:e15-7.

12. Lyda MH, Noffsinger A, Belli J, Fischer J, Fenoglio-Preiser CM. Multifocal neoplasia involving the colon and appendix in ulcerative colitis: pathological and molecular features. Gastroenterology. 1998;115:1566-73.

13. Suto A, Tsuyuki A, Hiraoka N, Hosoda Y, Kikuchi K, Fujishiro Y. Asymptomatic primary mucinous cystadenocarcinoma of the appendix with a large abdominal mass: report of a case. Surg Today. 1994:24:915-7.

14. Snyder TE, Vandivort MR. Mucinous cystadenocarcinoma of the appendix with pseudomyxoma peritonei presenting as total uterine prolapse. A case report. J Reprod Med. 1992;37:103-6.

15. Takahashi S, Furukawa T, Ueda J. Case report: mucocele of the tip of the appendix. Clin Radiol. 1998;53:149-50.
16. Zissin R, Gayer G, Kots E, Apter S, Peri M, Shapiro-Feinberg M. Imaging of mucocoele of the appendix with emphasis on the CT findings: a report of 10 cases. Clin Radiol. 1999;54:826-32.

17. Rutledge $\mathrm{RH}$, Alexander JW. Primary appendiceal malignancies: rare but important. Surgery. 1992;111:244-50.

18. Lo NS, Sarr MG. Mucinous cystadenocarcinoma of the appendix. The controversy persists: a review. Hepatogastroenterology. 2003;50:432-7.

19. McFarlane ME, Plummer JM, Bonadie K. Mucinous cystadenoma of the appendix presenting with an elevated carcinoembryonic antigen (CEA): report of two cases and review of the literature. Int J Surg Case Rep. 2013;4:886-8.

20. Lakatos PL, Gyori G, Halasz J, Fuszek P, Papp J, Jaray B, et al. Mucocele of the appendix: an unusual cause of lower abdominal pain in a patient with ulcerative colitis. A case report and review of literature. World J Gastroenterol. 2005; 11:457-9.

21. Pai RK, Beck AH, Norton JA, Longacre TA. Appendiceal mucinous neoplasms: clinicopathologic study of 116 cases with analysis of factors predicting recurrence. Am J Surg Pathol. 2009:33:1425-39.

22. Misdraji J, Yantiss RK, Graeme-Cook FM, Balis UJ, Young RH. Appendiceal mucinous neoplasms: a clinicopathologic analysis of 107 cases. Am J Surg Pathol. 2003:27:1089-103.

23. Rosai J. Rosai and Ackerman's surgical pathology. 10th ed. Maryland Heights: Mosby; 2011.

24. Carr NJ, Cecil TD, Mohamed F, Sobin LH, Sugarbaker PH, Gonzalez-Moreno $\mathrm{S}$, et al. A consensus for classification and pathologic reporting of pseudomyxoma peritonei and associated appendiceal neoplasia: the results of the Peritoneal Surface Oncology Group International (PSOGI) Modified Delphi Process. Am J Surg Pathol. 2016;40:14-26.

25. De Abreu Filho JG, De Lira EF. Mucocele of the appendix: appendectomy or colectomy? J Coloproctol. 2011;31:276-84.

26. Nitecki SS, Wolff BG, Schlinkert R, Sarr MG. The natural history of surgically treated primary adenocarcinoma of the appendix. Ann Surg. 1994;219:51-7.

27. UpToDate: Appendiceal mucoceles. UpToDate, Waltham. http://www.uptodate. $\mathrm{com} /$ contents/appendiceal-mucoceles? source=search_result\&search= appendiceal+mucocele\&selectedTitle=1 3. Accessed 5 Feb 2016

28. Turaga KK, Pappas S, Gamblin TC. Right hemicolectomy for mucinous adenocarcinoma of the appendix: just right or too much? Ann Surg Oncol. 2013; 20:1063-7.

29. Singh MK, Kumar MK, Singh R. Laparoscopic appendectomy for mucocele of the appendix. J Nat Sci Biol Med. 2014:5:204-6.

\section{Submit your next manuscript to BioMed Central and we will help you at every step:}

- We accept pre-submission inquiries

- Our selector tool helps you to find the most relevant journal

- We provide round the clock customer support

- Convenient online submission

- Thorough peer review

- Inclusion in PubMed and all major indexing services

- Maximum visibility for your research

Submit your manuscript at www.biomedcentral.com/submit
Biomed Central 